\title{
Strategi Peningkatan Daya Saing UMKM Di Kabupaten Sumenep Melalui E-COMMERCE
}

\author{
Moh. Kurdi, Imam Darul Firmansyah \\ FakultasEkonomi dan Bisnis, UniversitasWiraraja, Indonesia \\ Email author: kurdi.em@gmail.com/ imamdarul@wiraraja.ac.id
}

\begin{abstract}
ABSTRAK
Perkembangan teknologi informasi ini terus mengalami perkembangan yang sangat luar biasa. Istilah teknologi informasi (Information Technology) atau yang biasa disebut dengan IT, merupakan istilah yang umum dalam menggambarkan semua teknologi yang memudahkan manusia dalam menciptakan, merubah, menyimpan, mengkomunikasikan atau bahkan menyerbarluarkan informasi kepada orang lain. Walaupun perkembangan teknologi informasi semakin maju, namun sebagian besar UMKM yang ada belum memanfaatkan dengan optimal aplikasi e-commerce. tujuan khusus untuk merumuskan strategi-strategi yang perlu digunakan.Penelitian ini menggunakan deskriptif kualitatif dengan menggunakan analisis SWOT. Hasil dari penelitian ini menunjukkan bahwa perlunya strategi dalam meningkatkan daya saing UMKM yang ada di Kabupaten Sumenep. strategi yang harus digunakan dalam peningkatan daya saing adalah membangun kedekatan yang baik dengan pelanggan untuk menghindari penipuan dan kecurangan serta meningkatkan inovasi produk untuk menghindari palgiator dengan memperhatikan efisiensi biaya dalam meningkatkan penghasilan.
\end{abstract}

Kata Kunci: Strategi, Daya Saing, UMKM, E-Commerce

\section{PENDAHULUAN}

Keberadaan teknologi informasi pada saat sekarang ini, mempunyai peranan yang sangat penting dalam bagi kehidupan manusia. Perkembangan teknologi informasi ini terus mengalami perkembangan yang sangat luar biasa. Istilah teknologi informasi (Information Technology) atau yang biasa disebut dengan IT, merupakan istilah yang umum dalam menggambarkan semua teknologi yang memudahkan manusia dalam menciptakan, merubah, menyimpan, mengkomunikasikan atau bahkan menyerbarluarkan informasi kepada orang lain. Menurut Andriyanto (2019) "Teknologi informasi melakukan komputasi dan komunikasi berkecepatan tinggi untuk data, suara dan video". Pada saat ini dalam setiap melakukan kegiatan sehari-hari selalu didukung oleh teknologi informasi, dari memenuhi kebutuhan sehari-hari seperti mencari makanan, pakaian, pulsa, informasi untuk belanja, bahkan dijadikan alat untuk menjalankan usaha atau bisnis. Hal ini tidak hanya dilakukan oleh pengusaha kecil saja melainkan juga perusahaan yang sudah besar. Penggunaan informasi teknologi sudah hampir semua perusahaan besar sudah menggunakan dan memanfaatkan teknologi informasi sebagai alat pendukung seluruh aktifitas bisnis yang di kelola baik yang berbentuk offline maupun online. 
Selaras dengan perkembangan teknologi informasi yang ada, tingkat persaingan bisnis semakin menarik. Hal ini tidak hanya pada pasar offline tetapi juga pasar online. Sehingga persaingan yang tercipta diantara pelaku bisnis sangatlah kompetitif. Dengan demikian semua pelaku bisnis dituntut untuk lebih kreatif, inovatif, dan selalu memberikan yang terbaik dari produk yang di jual untuk dapat bersaing. Tidak sebatas produk yang harus diperhatikan, tetapi juga harus memikirkan strategi-strategi yang akan digunakan untuk mencapai tujuan dari perusahaan. Karena saat sekarang ini, perusahaan besar sudah banyak yang menggunakan internet atau yang biasa disebut dengan e-commerce.

Untuk dapat berperan dalam pengembangan ekonomi maka UMKM perlu adanya strategi-strategi dalam mengembangkan dan meningkatkan daya saing UMKM, salah satunya dengan penggunaan e-commerce. Walaupun perkembangan teknologi informasi semakin maju, namun sebagian besar UMKM yang ada belum memanfaatkan dengan optimal aplikasi e-commerce. Penyebab belum optimalnya penggunaan e-commerce pada UMKM di Kabupaten Sumenep tidak hanya faktor SDM saja melainkan banyak faktor diantaranya belum meratanya jaringan internet yang ada, logistik, dan bentuk pembayaran.

Dengan persaingan bisnis yang semakin kuat dan minimnya penggunaan ecommerce dalam pengembangan UMKM, maka perlu adanya kajian yang lebih mendalam mengenai strategi- strategi yang harus digunakan dan peningkatan daya saing UMKM merupakan yang sangat penting untuk dilakukan. Karena dengan kurangnya pemanfaatan e-commerce akan berdampak terhadap keberlangsung UMKM dan melemahnya tingkat daya saing dan ketertinggalan terhadap perusahaan yang besar yangsudah menggunakan e-commerce. Karena e-commerce merupakan pemasaran yang efektif dan sangat efisien dilakukan untuk saat ini.

\section{METODE PENELITIAN}

Penelitian ini merupakan penelitian deskriptif kualitatif yang dilakukan untuk memberikan gambaran yang secara detail mengenai suatu gejala atau fenomena dengan tujuan untuk mengetahui bagaimana peningkatakan daya saing UMKM melalui e-commerce. Proses pengumpulan data dilakukan terhadap data primer dan data sekunder. Pengumpulan data primer dilakukan dengan teknik kusioner, yaitu berupa daftar pertanyaan/pernyataan yang dibagikan kepada responden untuk diisi sesuai keadaan dan persepsi responden dengan responden sebanyak 60 UMKM. Metode analisis data digunakan untuk mengolah data yang diperoleh setelah pengadaan penelitian, sehingga akan didapat suatu kesimpulan tentang keadaan yang sebenarnya dari obyek yang penelitian. Analisis data yang digunakan dalam penelitian menggunakan analisis SWOT. 


\section{TEMUAN DAN PEMBAHASAN}

Secaraumumkeadaan pelaku UMKMyang ada di Kabupaten Sumenep akanberkembangdanbersaing jika menggunakan e-commerce. Untuk memaksimalkan penggunaan e-commerce maka perlu menggunakan strategi yang tepat.

Berdasarkan hasil analisis yang telah dilakukan sebelumnya oleh peneliti, faktor internal dan eksternal yang dimiliki oleh UMKM di Kabupaten Sumenepdapat dikombinasikan kedalam matriks posisi SWOT. UMKM di Kabupaten Sumenepdapat mengetahui posisi usaha pada saat ini melalui matriks posisi SWOT.

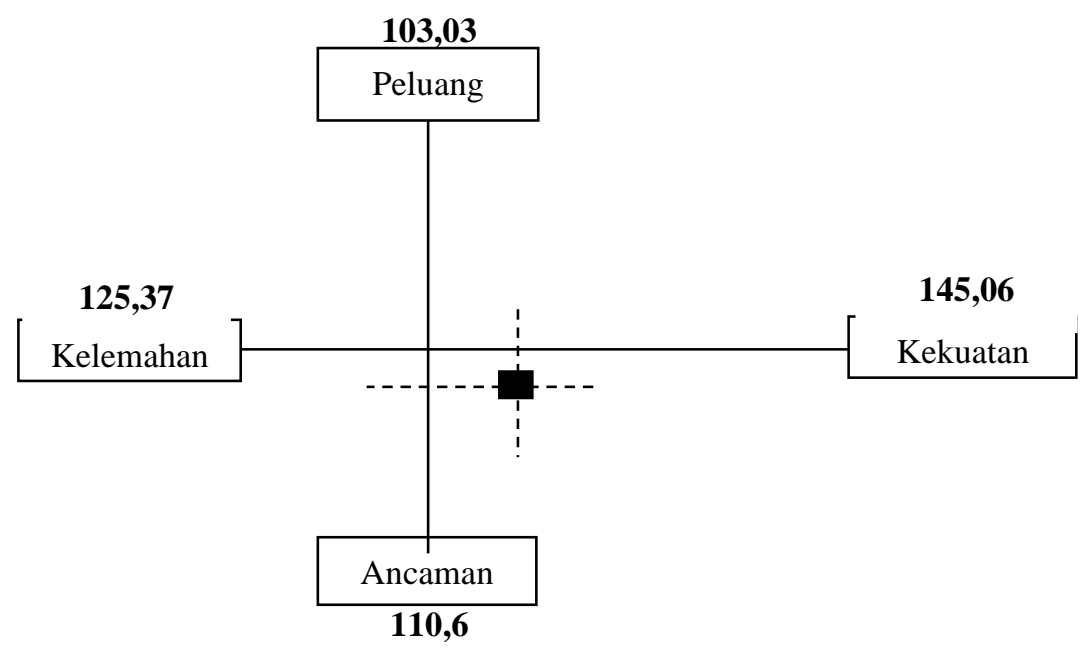

Gambar 1. Matriks Posisi SWOT

Perhitungan skor total dari analisis lingkungan internal (ALI) yang terdiri atas kekuatan dan kelemahan dengan skor total sebesar 270,4 sedangkan pada skor total dari analisis lingkungan eksternal (ALE) yang terdiri atas peluang dan ancaman dengan skor total sebesar 213,63. Dari skor yang diperoleh, kemudian dimasukkan pada diagram matriks posisi SWOT, sehingga bisa diketahui gambaran posisi pelaku UMKM di Kabupaten Sumenep saat ini.

Berdasarkan gambar matriks posisi SWOT diatas dapat diketahui bahwa posisi pelaku UMKM di Kabupaten Sumenep berada pada kuadran III, yang artinya kekuatan yang dimiliki harus bisa meminimalisir ancaman yang dimiliki oleh pelaku usaha UMKM di Kabupaten Sumenep. Untuk itu strategi yang perlu diterapkan oleh UMKM dalam kondisi tersebut yaitu mendukung kebijakan peningkatan daya saing UMKM.

Selain itu, faktor-faktor lain dalam peningkatan daya saing UMKM harus juga diperhatikan, baik faktor internal maupun faktor eksternal. Karena dalam peningkatan daya saing UMKM tidak akan pernah bisa dilepaskan dari beberapa faktor yang sudah ada. Faktor-faktor tersebut juga selain dapat menjadi bahan untuk kajian bagi pelaku UMKM juga dapat menjadi acuan untuk keberlanjutan UMKM. 
Berdasarkan gambar 1. diagram matrik SWOT diatas, maka dapat dirumuskan strategi pemasaran yang sesuai dengan situasi lingkungan internal dan eksternal pelaku usaha UMKM sebagai berikut:

Tabel 1. Diagram Matriks SWOT

\begin{tabular}{|c|c|c|}
\hline ALE & $\begin{array}{l}\text { Strengths }(S) \\
\text { 1. Jangkauan pasar yang sangat } \\
\text { luas } \\
\text { 2. Tidak terbatas oleh ruang dan } \\
\text { waktu } \\
\text { 3. Lebih dekat dengan } \\
\text { pelanggan } \\
\text { 4. Efisiensi biaya } \\
\text { 5. Kemudahan } \\
\text { bertransaksi dalam } \\
\text { 6. Meningkatkan penghasilan }\end{array}$ & \begin{tabular}{l}
\multicolumn{1}{c}{ Weaknesses $(W)$} \\
1. Persaingan ketat \\
2. Keterbatasan sarana IT \\
3. Kepercayaan penjual dan \\
pembeli \\
4. Biaya pengiriman yang \\
mahal \\
5. Memiliki kekuatan di pasar \\
tradisional \\
6. Keraguan konsumen dalam \\
kualitas barang
\end{tabular} \\
\hline Opportunities $(\mathrm{O})$ & Strategi S-O & $\begin{array}{l}\text { Strategi W-O } \\
\end{array}$ \\
\hline $\begin{array}{l}\text { 1. Kemudahan dalam } \\
\text { promosi dan pemasaran } \\
\text { 2. Kemudahan bertransaksi } \\
\text { 3. Tidak terbatas ruang dan } \\
\text { waktu } \\
\text { 4. Menciptakan pasar yang } \\
\text { baru } \\
\text { 5. Daya konsumsi } \\
\text { masyarakat yang tinggi } \\
\text { 6. Mengikuti perkembangan } \\
\text { zaman }\end{array}$ & $\begin{array}{l}\text { 1. Memanfaatkan pasar yang } \\
\text { sangat luas dan tidak terbatas } \\
\text { oleh ruang dan waktu denga } \\
\text { efisiensi biaya untuk } \\
\text { melakukan promosi dan } \\
\text { pemasaran guna menciptakan } \\
\text { pasar yang baru. } \\
\text { 2. Memperhatikan keinginan } \\
\text { pelanggan untuk terus } \\
\text { mengikuti perkembangan } \\
\text { zaman dengan kemudahan } \\
\text { transaksi demi meningkatkan } \\
\text { penghasilan. }\end{array}$ & $\begin{array}{l}\text { 1. Meningkatkan promosi dan } \\
\text { pemasaran dengan } \\
\text { memperhatikan keinginan } \\
\text { pasar dan konsumen untuk } \\
\text { memberikan kepercayaan } \\
\text { dan mengurangi keraguan } \\
\text { konsumen. } \\
\text { 2. Menciptakan produk yang } \\
\text { baru dengan mengikuti } \\
\text { perkembangan zaman } \\
\text { dalam menghadapi } \\
\text { persaingan pasar yang ketat } \\
\text { dengan memanfaatkan } \\
\text { sarana IT. }\end{array}$ \\
\hline Threaths (T) & & Strategi W-T \\
\hline $\begin{array}{l}\text { 1. Pesaing yang sangat } \\
\text { banyak } \\
\text { 2. Munculnya Plagiator } \\
\text { 3. Tidak adanya privasi } \\
\text { 4. Rawan Penipuan dan } \\
\text { Kecurangan } \\
\text { 5. Ancaman keamanan } \\
\text { 6. Inovasi produk yang } \\
\text { harus selalu dilakukan } \\
\text { yang tidak stabil }\end{array}$ & $\begin{array}{l}\text { 1. Membangun kedekatan yang } \\
\text { baik dengan pelanggan untuk } \\
\text { menghindari penipuan dan } \\
\text { kecurangan. } \\
\text { 2. Meningkatkan r inovasi } \\
\text { produk untuk menghindari } \\
\text { palgiator } \\
\text { memperhatikan dengan } \\
\text { biaya dalam meningkatkan } \\
\text { penghasilan }\end{array}$ & $\begin{array}{l}\text { 1. Meningkatan } r \text { inovasi } \\
\text { produk untuk menghindari } \\
\text { persaing dan plagiator } \\
\text { untuk } \quad \text { memberikan } \\
\text { kepercayaan kepada } \\
\text { konsumen dan mengurangi } \\
\text { penipuan dan kecurangan. } \\
\text { 2. Melakukan pembenahan IT } \\
\text { dalam melindungi ancaman } \\
\text { keamanan r untuk } \\
\text { menghindari persaingan } \\
\text { yang sangat ketat dan } \\
\text { banyak. }\end{array}$ \\
\hline
\end{tabular}

Berdasarkan gambar dan tabel dan gambar diatas bahwa dalam menjalankan UMKM perlu mengetahui strategi yang tepat agar UMKM mendapatkan keuntungan dan mampu berkembang dengan baik. Sehingga dalam penelitian ini dapat dirumuskan 
strategi yang tepat untuk meingkatkan daya saing UMKM di Kabupaten Sumenep sesuai dengan posisi strategi.

Rumusan strategi dibuat dengan meningkat kakekuatan dan mengurangi kelemahan yang dimiliki,serta menangkap peluang untuk menghadapi ancaman. Dari beberapa alternatef strategi yang ada, maka pelaku UMKM di KabupatenSumenep harus menggunakan strategi yang tepat. Penggunaan strategi ini untuk mendukung peningkatan daya saing UMKM melaluipengunaana e-commerce.Formulasistrategi yang harusdigunakanadalahmembangun kedekatan yang baik dengan pelanggan untuk menghindari penipuan dan kecurangan serta meningkatkan inovasi produk untuk menghindari palgiator dengan memperhatikan efisiensi biaya dalam meningkatkan penghasilan.

Dari strategi tersebut dapat diartikan bahwa pelaku UMKM lebih membangun kedekatan dengan konsumen dengan cara berperan aktif melakukan komunikasi dengan pelanggan untuk membangun kepercayaan dengan konsumen sehingga hal ini dapat menghindari dan mengurangi adanya penipuan dan kecurangan. Karena dengan dengan demikian konsumen akan lebih percaya terhadap pelaku UMKM. Selain itu, pelaku UMKM di Kabupaten Sumenep pelaku UMKM harus selalu melalukan pengembangan dan inovasi produk yang sudah ada untuk dapat bersaing dengan produk yang terus berkembang, sehingga konsumen akan merasakan kepuasan dan selalu merasa diperhatikan oleh pelaku UMKM. Tetapi yang perlu diperhatikan oleh pelaku UKMK adalah harus menghindari plagiat terhadap produk lain.

Dengan penggunaan e-commerce akan mengurangi pengunaan biaya yang lebih efisien dan dapat meningkatkan penghasilan. Dengan demikian pemanfaatan ecommerce pada pelaku UMKM akan lebih bermanfaat dan berguna dengan menerapkan formulasi strategi yang tepat dan benar.

\section{KESIMPULAN DAN SARAN}

Dan hasil analisis SWOT yang dilakukan menunjukkan bahwa posisi pelaku UMKM Kabupaten Sumenepp berada pada kuadran III yaitu Defensive Strategy, dimana pelaku usaha hars bisa memanfaatkan kekuatan untuk meminimalisir ancaman. Maka Strategi yang bisa diterapkan untuk peningkatan daya saing UMKM di Kabupaten Sumenep adalah membangun kedekatan yang baik dengan pelanggan untuk menghindari penipuan dan kecurangan serta meningkatkan inovasi produk untuk menghindari palgiator dengan memperhatikan efisiensi biaya dalam meningkatkan penghasilan. 


\section{DAFTAR PUSTAKA}

Andriyanto, I. (2019). Penguatan Daya Saing Usaha Mikro Kecil Menengah Melalui ECommerce. BISNIS: Jurnal Bisnis Dan Manajemen Islam. https://doi.org/10.21043/bisnis.v6i2.4709

Pratama, F. C. (2019). CUSTOMER RELATIONSHIP MANAGEMENT SEBAGAI STRATEGI MENCAPAI KEUNGGULAN BERSAING BERKELANJUTAN PENGGILINGAN PADI. Ekonomi Bisnis. https://doi.org/10.17977/um042v24i2p80-87

KBBI. (2019). KBBI - Kamus Besar Bahasa Indonesia. Kamus Besar Bahasa Indonesia.

Ariani, A., \& Utomo, M. N. (2017). KAJIAN STRATEGI PENGEMBANGAN USAHA MIKRO KECIL DAN MENENGAH (UMKM) DI KOTA TARAKAN. Jurnal Organisasi Dan Manajemen. https://doi.org/10.33830/jom.v13i2.55.2017

Pujiono, A., Setyawati, R., \& Idris, I. (2018). STRATEGI PENGEMBANGAN UMKM HALAL DI JAWA TENGAH DALAM MENGHADAPI PERSAINGAN GLOBAL. Indonesia Journal of Halal. https://doi.org/10.14710/halal.v1i1.3109

Rakanita, A. M. (2019). PEMANFAATAN E-COMMERCE DALAM MENINGKATKAN DAYA SAING UMKM DI DESA KARANGSARI KECAMATAN KARANGTENGAH KABUPATEN DEMAK. JURNAL EKBIS. https://doi.org/10.30736/ekbis.v20i2.237

Meliala, A. S., Matondang, N., \& Sari, R. M. (2016). Strategi Peningkatan Daya Saing Usaha Kecil dan Menengah (UKM) Berbasis Kaizen. Jurnal Optimasi Sistem Industri. https://doi.org/10.25077/josi.v13.n2.p641-664.2014

Undang-Undang No. 20 Tahun 2008. (2008). Tentang: Usaha,Mikro,Kecil dan Menengah. Sekretariat Negara. Jakarta.

Anggaranie, G. (2017). Perkembangan E-Commerce Beserta Klasifikasinya. Retrieved from www.SupplyChainIndonesia.com

Irawati, D. A., David, F., Ekojono, E., \& Pramitarini, Y. (2018). Desain Model Sistem Marketplace Untuk Koperasi Di Indonesia. Seminar Nasional Informatika (SEMNASIF).

Soia, A., Konnikova, O., \& Konnikov, E. (2019). The internet of things. In Proceedings of the 33rd International Business Information Management Association Conference, IBIMA 2019: Education Excellence and Innovation Management through Vision 2020. https://doi.org/10.4018/ijhiot.2018010101

Supriyanto, A. S., Ekowati, V. M., \& Masyhuri, M. (2019). The Relationship among Spiritual Intelligence, Emotional Intelligence, Organizational Citizenship Behaviour, and Employee Performance. ETIKONOMI. https://doi.org/10.15408/etk.v18i2.11318

Fatmawati, \& Kurdi, M. (2018). Analysis and Business Development Strategy Agroindustry Herbal. Journal Of Agricultural Science And Agriculture Engineering, 2(1), 45-56. Retrieved from http://agriscience.scientific- 
work.org/index.php/agriscience/article/view/27/23

Alyas, -. (2017). STRATEGI PENGEMBANGAN USAHA KECIL DAN MENENGAH DALAM PENGUATAN EKONOMI KERAKYATAN (Studi Kasus pada Usaha Roti Maros di Kabupaten Maros). Sosiohumaniora. https://doi.org/10.24198/sosiohumaniora.v19i2.12249 